\title{
Reliability Study of the AP1000 Passive Safety System by Fuzzy Approach
}

\author{
J.H. Purba* and D.T. Sony Tjahyani \\ Center for Nuclear Reactor Technology and Safety, National Nuclear Energy Agency, \\ Puspiptek Area, Serpong, Tangerang 15310, Indonesia
}

\section{ARTICLE INFO}

\section{Article history:}

Received 08 November 2013

Received in revised form 28 May 2014

Accepted 02 June 2014

\section{Keywords:}

Fuzzy reliability approach

Failure possibility

Triangular fuzzy numbers

Passive safety system

AP1000

\begin{abstract}
A B S T R A C T
The Westinghouse AP1000 is a new design nuclear power plant which has implemented the concept of passive system. Even though a passive system may be more reliable than an active one, the possibility of the passive system to fail still exists. In line with this possibility, generic database have been used to study the reliability of the AP1000 passive safety system. However, since the used data are not specific to the AP1000, the results of the analysis will not show its real performance. This study proposes a fuzzy reliability approach to overcome this problem. The proposed fuzzy reliability approach utilizes the concept of failure possibility to qualitatively describe basic event likely occurences and membership functions of triangular fuzzy numbers to quantitatively represent qualitative failure possibilities. A case-based experiment on reliability study of the AP1000 passive safety system involved to mitigate a large break loss of collant accident is used to validate the feasibility of the proposed approach. By comparisons, probabilities of basic events generated by the proposed approach are very close to the ones which have been used by previous reliability studies. This can be observed from the small numbers of relative errors, i.e. between 0.004125 and 0.079635 . These results confirm that the fuzzy reliability approach offers a more realistic technique to study the reliability of the AP1000 passive safety system, without the need to engage to precise probability distributions of its components which are currently unavailable.
\end{abstract}

\section{INTRODUCTION}

The performance of the safety systems of nuclear power plants, which ensures that the plants can normally operate without an excessive risk exposure to staffs and environment, prevents accidents and mitigates the consequences of accidents if they occur, is a very important factor to enhance nuclear energy options. In line with this, the concepts of passive systems have been the focus of recent innovations to the designs of nuclear power plant safety systems. The Westinghouse AP1000 is a two-loop advanced light water reactor which implements passive concept to its safety systems based on gravity, convection, condensation and heat circulation [1-5]. AP1000 has been certified as a generation III+ reactor by the United States Nuclear Energy Commission (US-NRC) and the European Utility Requirements [6,7]. AP1000 design offers four advantageous, i.e. high reliability, human error minimization, simplification and easy modularization [8]. It is the first commercial nuclear

\footnotetext{
* Corresponding author.

E-mail address: purba-jh@batan.go.id
}

power plant design whose all safety features depend on passive systems [9] and is currently under construction in China $[4,10,11]$. Even though, a passive system may be more reliable than an active system [5], the possibility of the passive system to fail still exists due to the failures of the passive system itself to response to the physical phenomenon in which it is based on. Therefore, the reliability of AP1000 passive safety system still needs to be studied by considering many possible different accident scenarios.

Meanwhile, fault tree analysis has been widely used to evaluate the reliability of the safety systems of nuclear power plants. It provides a comprehensive and structured approach to identify and understand key plant vulnerabilities, to develop accident scenarios, to assess the level of plant safety, and to derive numerical estimates of potential risks $[12,13]$. To perform this analysis, safety analysts have to provide reliability data of all basic events of the system fault tree being evaluated.

Since AP1000 is still under construction, safety analysts have to use generic database to study the reliability of its passive safety system. For example, generic database has been used in 
Kamyab et al. [14] and in Kamyab and Nematollahi [15] to evaluate to what extend the passive core cooling system can affect the final core damage frequency of AP1000. Meanwhile, Guimaraes et al. [16] used generic database to study the reliability of the AP1000 passive safety system to mitigate large break loss of coolant accident (LOCA). In addition, Zhou et al. [17] used generic database to evaluate the reliability of the AP1000 passive residual heat removal system. Those generic databases may be taken from other nuclear power plants or nuclear industries other than nuclear power plants.

However, since component reliability data used in those previous AP1000 reliability study are not taken from the AP1000 operating experiences, the results of the analysis do not actually show the real performance of its passive safety system. Moreover, safety analysts have to deal with imprecision and uncertainties arising from the generic database. To deal with these drawbacks, a new approach should be proposed and applied to evaluate reliability characteristic of components of the AP1000 passive safety system without the need to engage to historical failure data which are currently unavailable.

In the meantime, fuzzy reliability approach has been developed and successfully applied for reliability study of existing nuclear power plants [18-20]. It utilizes the concept of failure possibilities to qualitatively describe component failure characteristics and membership functions of triangular fuzzy numbers to represent qualitative failure possibilities in mathematical form. Hence, the motivation of this study is to propose and implement the fuzzy reliability approach to evaluate the reliability of components of the AP1000 passive safety system. A case-based experiment on the reliability study of the AP1000 passive system involved to mitigate a large break LOCA is then used to mathematically illustrate the feasibility of the proposed approach.

\section{AP1000 passive safety system to mitigate a large break loca}

Loss of coolant accident (LOCA) is one of many postulated accidents that might occur in nuclear power plants. LOCA is defined as an accident in which reactor coolant pressure boundary breaks to freely discharge reactor coolant. LOCA which is caused by a large break in the primary coolant system is a design basis accident for pressurized water reactors [21].

The primary coolant system of the AP1000 whose function to circulate coolant between the reactor core and the steam generators involves two loops of heat transfer systems and one pressurizer. Each loop consists of one steam generator, two reactor coolant pumps, one hot leg, and two cold legs as shown in Fig. 1 [7].

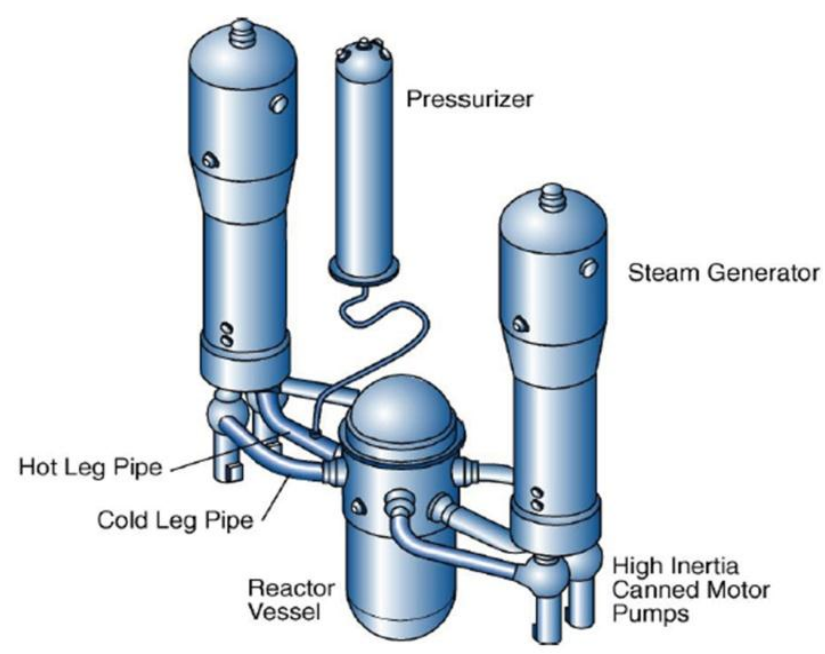

Fig. 1. AP1000 reactor coolant system.

AP1000, which is designed based on the Westinghouse proven pressurized water reactors $[22,23]$, has implemented the concept of passive system into its safety injection system, residual heat removal system and containment cooling system. The major advantage of these passive safety systems is that the long-term accident mitigation can be maintained without the involvement of the operators and reliance on the AC power sources from offsite or onsite [3,9].

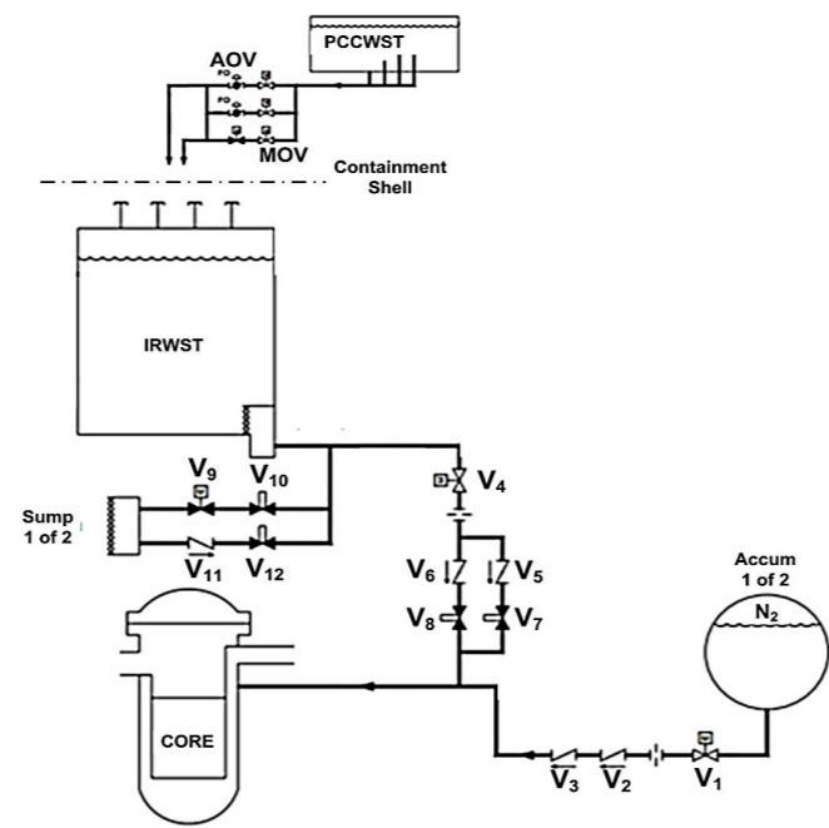

Fig. 2. AP1000 passive safety system to mitigate a large break LOCA. 
AP1000 reactors provide three passive safety systems to mitigate the large break LOCA, namely: injection system by accumulator (AI), low pressure injection system (LPI) which injects water from in-containment refueling water storage tank (IRWST) and long term cooling system (LTC) which injects water from passive containment cooling water storage tank (PCCWST) [16]. Figure 2 shows the simplified schema of the working process of those three safety systems.

A number of valves are aligned to automatically actuate those three passive safety systems by shifting the valve positions. To provide high reliability, those valves are automatically actuated to their safeguard positions when they loss of power or receive actuation signal [23]. The description of the passive injection system by accumulator, passive low pressure injection system and passive long term cooling system and their corresponding fault trees as well as the probabilities of basic events used to study the reliability of the AP1000 passive safety system can be read in details in Guimaraes et al. [16]. Table 1 shows the probabilities of basic events of the three safety systems in Fig. 2 which function to mitigate the AP1000 large break LOCA. By assuming that those reliability data are relevant for studying the reliability of the AP1000 passive safety system, we then use those data to benchmark our proposed approach. To confirm the feasibility of the fuzzy reliability approach, it has to generate probabilities of basic events as closes as possible to the ones given in Table 1.

Table 1. Probabilities of basic events involved to mitigate the AP1000 large break LOCA.

\begin{tabular}{clc}
\hline Basic event IDs & Component Failures & Probabilities \\
\hline$b_{1}$ & The failure of $V_{1}$ & $7.59 \mathrm{E}-6$ \\
$b_{2}$ & The failure of $V_{2}$ & $1.11 \mathrm{E}-5$ \\
$b_{3}$ & The failure of $V_{3}$ & $1.11 \mathrm{E}-5$ \\
$b_{4}$ & The failure of $V_{4}$ & $7.59 \mathrm{E}-6$ \\
$b_{5}$ & The failure of $V_{5}$ & $1.11 \mathrm{E}-5$ \\
$b_{6}$ & The failure of $V_{6}$ & $1.11 \mathrm{E}-5$ \\
$b_{7}$ & The failure of $V_{7}$ & $1.90 \mathrm{E}-4$ \\
$b_{8}$ & The failure of $V_{8}$ & $1.90 \mathrm{E}-4$ \\
$b_{9}$ & The failure of $V_{9}$ & $1.06 \mathrm{E}-4$ \\
$b_{10}$ & The failure of $V_{10}$ & $1.90 \mathrm{E}-4$ \\
$b_{11}$ & The failure of $V_{11}$ & $1.11 \mathrm{E}-5$ \\
$b_{12}$ & The failure of $V_{12}$ & $1.90 \mathrm{E}-4$ \\
$b_{13}$ & The failure of $A O V$ & $1.21 \mathrm{E}-4$ \\
$b_{14}$ & The failure of $M O V$ & $7.59 \mathrm{E}-6$ \\
\hline & & \\
\hline
\end{tabular}

\section{EXPERIMENTAL METHODS}

\section{Methodology}

Fuzzy reliability approach is used in this study to generate the probabilities of those basic events in Table 1. It applies seven terms of failure possibilities to qualitatively describe basic event likely occurences and seven membership functions of triangular fuzzy numbers to represent those qualitative reliability characteristics in mathematical form as shown in Table 2 [18].

Table 2. Qualitative failure possibilities and the corresponding failure likelihood values and membership functions.

\begin{tabular}{|c|c|c|}
\hline $\begin{array}{c}\text { Failure } \\
\text { possibilities }\end{array}$ & $\begin{array}{l}\text { Failure } \\
\text { likelihood } \\
\text { values }\end{array}$ & Membership functions \\
\hline Very Low $\left(h_{l}\right)$ & $<1.0 \mathrm{E}-8$ & $\begin{array}{l}\mu_{1}(x)=\mu_{\text {Very Low }}(x) \\
=(0.00,0.04,0.08)\end{array}$ \\
\hline $\operatorname{Low}\left(h_{2}\right)$ & $1.0 \mathrm{E}-8-1.0 \mathrm{E}-7$ & $\begin{array}{l}\mu_{2}(x)=\mu_{\text {Low }}(x) \\
=(0.07,0.13,0.19)\end{array}$ \\
\hline $\begin{array}{l}\text { Reasonably } \\
\text { Low }\left(h_{3}\right)\end{array}$ & $1.0 \mathrm{E}-7-1.0 \mathrm{E}-6$ & $\begin{array}{l}\mu_{3}(x)=\mu_{\text {Reasonably Low }}(x) \\
=(0.17,0.27,0.37)\end{array}$ \\
\hline Moderate $\left(h_{4}\right)$ & $1.0 \mathrm{E}-6-1.0 \mathrm{E}-5$ & $\begin{array}{l}\mu_{4}(x)=\mu_{\text {Moderate }}(x) \\
=(0.35,0.50,0.65)\end{array}$ \\
\hline $\begin{array}{l}\text { Reasonably } \\
\operatorname{High}\left(h_{5}\right)\end{array}$ & $1.0 \mathrm{E}-5-1.0 \mathrm{E}-4$ & $\begin{array}{l}\mu_{5}(x)=\mu_{\text {Reasonably High }}(x) \\
=(0.63,0.73,0.83)\end{array}$ \\
\hline $\operatorname{High}\left(h_{6}\right)$ & $1.0 \mathrm{E}-4-1.0 \mathrm{E}-3$ & $\begin{array}{l}\mu_{6}(x)=\mu_{\text {High }}(x) \\
=(0.81,0.87,0.93)\end{array}$ \\
\hline Very High $\left(h_{7}\right)$ & $>1.0 \mathrm{E}-3$ & $\begin{array}{l}\mu_{7}(x)=\mu_{\text {Very High }}(x) \\
=(0.92,0.96,1.00)\end{array}$ \\
\hline
\end{tabular}

The quantification process of the fuzzy reliability approach to generate probabilities of basic events of fault trees consists of five steps which can be described as follows.

\section{Step 1: Basic event likely occurrence evaluation}

The objective of this step is to generate a matrix of failure possibilities $(Q l)$ to express the likely occurrences of a set of basic events $(B)$ of a system fault tree $(F T)$ being evaluated. These failure possibilities are subjectively and individually assessed by a set of experts $(E)$ based on their expertise, working experiences and scientific intuition. An expert is a person who is familiar with the system being evaluated, understands its working environment, and has considerable training in and knowledge of its operation.

$$
\begin{aligned}
Q l & =\left[\begin{array}{ccccc}
h_{i}^{e_{1} b_{1}} & h_{i}^{e_{2} b_{1}} & h_{i}^{e_{3} b_{1}} & \cdots & h_{i}^{e_{n} b_{1}} \\
h_{i}^{e_{1} b_{2}} & h_{i}^{e_{2} b_{2}} & h_{i}^{e_{3} b_{2}} & \cdots & h_{i}^{e_{n} b_{2}} \\
h_{i}^{e_{1} b_{3}} & h_{i}^{e_{2} b_{3}} & h_{i}^{e_{3} b_{3}} & \cdots & h_{i}^{e_{n} b_{3}} \\
\vdots & \vdots & \vdots & \vdots & \vdots \\
h_{i}^{e_{1} b_{l}} & h_{i}^{e_{2} b_{l}} & h_{i}^{e_{3} b_{l}} & \cdots & h_{i}^{e_{n} b_{l}}
\end{array}\right] \\
B & =\left\{b_{k}: k=1-l\right\} \text { and } B \in F T \\
E & =\left\{e_{j}: j=1-n\right\}
\end{aligned}
$$


where $h_{i}^{e_{j} b_{k}}$ is the $i^{\text {th }}$ failure possibility in Table 2 to express the likely occurrence of basic event $b_{k}$ in (2) which is evaluated by expert $e_{j}$ in (3), $l$ is the number of basic events and $n$ is the number of experts. For example, if the likely occurence of basic event $b_{2}$ is evaluated by expert $e_{3}$ to be Very Low and from Table 2 we can see that Very Low is defined as the first failure possibility, therefore $h_{i}^{e_{j} b_{k}}=h_{1}^{e_{3} b_{2}}$.

Basic event likely occurences could be collected from the set of experts by asking questions assuming the form:

What is the likely occurence of basic event $b_{i}$ ? Is it "Very Low", "Low", "Reasonably Low", "Moderate”, "Reasonably High", "High”, or "Very High"?

To correlate experts' credibility to their judgments, different justification weights from 0 to 1 may be assigned to each expert as in (4).

$$
W=\left\{w_{1}, w_{2}, \cdots, w_{n} ; 0 \leq w_{i} \leq 1 ; \sum_{i=1}^{n} w_{i}=1\right\}
$$

where $w_{i}$ is the weight of the $i^{\text {th }}$ expert. An expert with a weight of 1 is the most credible, whilst an expert with a lower weight is deemed to be less credible.

\section{Step 2: Failure possibility fuzzification}

The objective of this step is to generate a matrix of membership functions $(Q n)$ of the failure possibility matrix $(Q l)$ generated in Step 1 . The matrix $Q n$ in (5) consists of only membership functions of triangular fuzzy numbers taken from Table 2.

$$
Q n=\left[\begin{array}{ccccc}
\mu_{i}^{e_{1} b_{1}}(x) & \mu_{i}^{e_{2} b_{1}}(x) & \mu_{i}^{e_{3} b_{1}}(x) & \cdots & \mu_{i}^{e_{n} b_{1}}(x) \\
\mu_{i}^{e_{1} b_{2}}(x) & \mu_{i}^{e_{2} b_{2}}(x) & \mu_{i}^{e_{3} b_{2}}(x) & \cdots & \mu_{i}^{e_{n} b_{2}}(x) \\
\mu_{i}^{e_{1} b_{3}}(x) & \mu_{i}^{e_{2} b_{3}}(x) & \mu_{i}^{e_{3} b_{3}}(x) & \cdots & \mu_{i}^{e_{n} b_{3}}(x) \\
\vdots & \vdots & \vdots & \vdots & \vdots \\
\mu_{i}^{e_{1} b_{l}}(x) & \mu_{i}^{e_{2} b_{l}}(x) & \mu_{i}^{e_{3} b_{l}}(x) & \cdots & \mu_{i}^{e_{n} b_{l}}(x)
\end{array}\right]
$$

where $\mu_{i}^{e_{j} b_{k}}(x)$ is the corresponding membership functions for the $h_{i}^{e_{j} b_{k}}$. For example, if the $h_{i}^{e_{j} b_{k}}=$ $h_{1}^{e_{3} b_{2}}$ then $\mu_{i}^{e_{j} b_{k}}(x)=\mu_{1}^{e_{3} b_{2}}(x)=\mu_{\text {Very Low }}(x)=$ $(0.00,0.04,0.08)$.

\section{Step 3: Final membership function generation}

The objective of this step is to generate a set of final membership functions $\left(M^{B}\right)$ for the set $B$ defined in (2) by multiplying the membership function matrix $(Q n)$ generated in Step 2 with the corresponding experts' weight defined in (4) as shown in (6).

$$
M^{B}=\left[\begin{array}{c}
\mu^{b_{1}}(x) \\
\mu^{b_{2}}(x) \\
\mu^{b_{3}}(x) \\
\vdots \\
\mu^{b_{l}}(x)
\end{array}\right]=Q n \times\left[\begin{array}{c}
w_{1} \\
w_{2} \\
w_{3} \\
\vdots \\
w_{n}
\end{array}\right]
$$

where $\mu^{b_{i}}(x)$ is the final membership function for the $i^{\text {th }}$ basic event and $w_{i}$ is the weight of the $i^{\text {th }}$ expert.

\section{Step 4: Membership function defuzzification}

The objective of this step is to generate a set of failure possibility scores $\left(R_{S}{ }^{B}\right)$ of the set of final membership functions $\left(M^{B}\right)$ generated in Step 3. A failure possibility score represents the experts' belief of the most likely score to indicate that an event may occur. It is decoded from a final membership function using an area defuzzification technique $(A D T)$ as in (7).

$$
R_{S}{ }^{B}=\left[\begin{array}{c}
R_{s}^{b_{1}} \\
R_{s}^{b_{2}} \\
R_{s}^{b_{3}} \\
\vdots \\
R_{S}^{b_{l}}
\end{array}\right]=\left[\begin{array}{c}
A D T\left(\mu^{b_{1}}(x)\right) \\
A D T\left(\mu^{b_{2}}(x)\right) \\
A D T\left(\mu^{b_{3}}(x)\right) \\
\vdots \\
A D T\left(\mu^{b_{l}}(x)\right)
\end{array}\right]
$$

$R_{S}^{b_{i}}$ is a failure possibility score for the $i^{\text {th }}$ basic event which is defuzzified from its final membership function $\left(\mu^{b_{i}}(x)\right)$.

The $A D T$ for the membership functions of triangular fuzzy numbers $\mu(x)=(a, b, c)$ can be calculated using (8) [24].

$$
A D T(\mu(x))=\frac{1}{18}(4 a+b+c)
$$

\section{Step 5 : Basic event probability generation}

The objective of this step is to generate a set of probabilities $\left(R^{B}\right)$ from the set of failure possibility scores $\left(R_{S}{ }^{B}\right)$ generated in Step 4 as shown in (9).

$$
R^{B}=\left[\begin{array}{c}
R^{b_{1}} \\
R^{b_{2}} \\
R^{b_{3}} \\
\vdots \\
R^{b_{l}}
\end{array}\right]=\left[\begin{array}{c}
f\left(R_{s}^{b_{1}}\right) \\
f\left(R_{s}^{b_{2}}\right) \\
f\left(R_{s}^{b_{3}}\right) \\
\vdots \\
f\left(R_{s}^{b_{l}}\right)
\end{array}\right]
$$

where $f\left(R_{s}^{b_{l}}\right)$ is a logarithmic function as shown in (10) [18]. 


$$
f\left(R_{S}^{b_{i}}\right)=\left\{\begin{array}{cl}
\frac{1}{\left[\frac{1-R_{S}^{b_{i}}}{b_{i}}\right]^{1 / 3} \times 2.301} & \text { if } R_{S}^{b_{i}} \neq 0 \\
0 & \text { if } R_{S}^{b_{i}}=0
\end{array}\right.
$$

\section{Mathematical illustration}

We can see from Table 1 that there are 14 basic events whose probabilities to be evaluated by the fuzzy reliability approach described in the previous sub-section as denoted in (11).

$B=\left\{b_{1}, b_{2}, b_{3}, b_{4}, b_{5}, b_{6}, b_{7}, b_{8}, b_{9}, b_{10}, b_{11}, b_{12}, b_{13}, b_{14}\right\}$

Let us assume that seven experts have been selected to evaluate the probabilities of those basic events in (11) as denoted in (12). To simplify the quantification process, let us also assume that those seven experts have the same level of expertise and hence the same justification weights of $1 / 7 \mathrm{~s}$ are assigned to each expert as denoted in (13).

$$
\begin{aligned}
& E=\left\{e_{1}, e_{2}, e_{3}, e_{4}, e_{5}, e_{6}, e_{7}\right\} \\
& W=\left\{w_{1}, w_{2}, w_{3}, w_{4}, w_{5}, w_{6}, w_{7} ; w_{i}=\frac{1}{7}\right\}
\end{aligned}
$$

In real implementation, these experts should be properly selected and weighted. Experts may be selected by considering their publications and working experiences related to the AP1000 passive safety system. Recommendations from a wide range of experts can be another important point for the expert selection $[18,19]$.

Using the format of questions described in the previous sub-section, each expert in (12) subjectively and individually evaluates the likely occurrences of those basic events in Table 1 and the experts' justification results are given in Table 3.

Table 3. Likely occurences of basic events in Table 1 evaluated by experts.

\begin{tabular}{cccccccc}
\hline \multirow{2}{*}{ Basic event IDs } & \multicolumn{7}{c}{ Basic event likely occurences evaluated by } \\
\cline { 2 - 8 } & $\boldsymbol{e}_{1}$ & $\boldsymbol{e}_{2}$ & $\boldsymbol{e}_{3}$ & $\boldsymbol{e}_{4}$ & $\boldsymbol{e}_{5}$ & $\boldsymbol{e}_{6}$ & $\boldsymbol{e}_{7}$ \\
\hline$b_{1}$ & $h_{4}$ & $h_{3}$ & $h_{3}$ & $h_{3}$ & $h_{3}$ & $h_{3}$ & $h_{3}$ \\
$b_{2}$ & $h_{4}$ & $h_{2}$ & $h_{3}$ & $h_{4}$ & $h_{3}$ & $h_{4}$ & $h_{2}$ \\
$b_{3}$ & $h_{4}$ & $h_{2}$ & $h_{3}$ & $h_{4}$ & $h_{3}$ & $h_{4}$ & $h_{2}$ \\
$b_{4}$ & $h_{4}$ & $h_{3}$ & $h_{3}$ & $h_{3}$ & $h_{3}$ & $h_{3}$ & $h_{3}$ \\
$b_{5}$ & $h_{4}$ & $h_{2}$ & $h_{3}$ & $h_{4}$ & $h_{3}$ & $h_{4}$ & $h_{2}$ \\
$b_{6}$ & $h_{4}$ & $h_{2}$ & $h_{3}$ & $h_{4}$ & $h_{3}$ & $h_{4}$ & $h_{2}$ \\
$b_{7}$ & $h_{5}$ & $h_{4}$ & $h_{5}$ & $h_{4}$ & $h_{5}$ & $h_{4}$ & $h_{5}$ \\
$b_{8}$ & $h_{5}$ & $h_{4}$ & $h_{5}$ & $h_{4}$ & $h_{5}$ & $h_{4}$ & $h_{5}$ \\
$b_{9}$ & $h_{4}$ & $h_{5}$ & $h_{4}$ & $h_{4}$ & $h_{4}$ & $h_{5}$ & $h_{4}$ \\
$b_{10}$ & $h_{5}$ & $h_{4}$ & $h_{5}$ & $h_{4}$ & $h_{5}$ & $h_{4}$ & $h_{5}$ \\
$b_{11}$ & $h_{4}$ & $h_{2}$ & $h_{3}$ & $h_{4}$ & $h_{3}$ & $h_{4}$ & $h_{2}$ \\
$b_{12}$ & $h_{5}$ & $h_{4}$ & $h_{5}$ & $h_{4}$ & $h_{5}$ & $h_{4}$ & $h_{5}$ \\
$b_{13}$ & $h_{5}$ & $h_{4}$ & $h_{3}$ & $h_{4}$ & $h_{5}$ & $h_{4}$ & $h_{5}$ \\
$b_{14}$ & $h_{3}$ & $h_{3}$ & $h_{4}$ & $h_{3}$ & $h_{3}$ & $h_{3}$ & $h_{3}$ \\
\hline
\end{tabular}

where $h_{2}=$ Low, $h_{3}=$ Reasonably Low, $h_{4}=$ Moderate, and $h_{5}=$ Reasonably High (refer to Table 2).

Those justification results in Table 3 are just of illustrative character of experts to obtain the closest matching probabilities of basic events to the known values. In real implementation, these justification results should be directly obtained from the selected experts in (12).

To mathematically illustrate how the fuzzy reliability approach generates the probabilities of basic events of the AP1000 passive safety system involved to mitigate the large break LOCA, we choose only two basic events from Table 1, i.e. $b_{1}$ and $b_{12}$. Basic event $b_{1}$ is chosen to show that the approach can generate a probability as low as $b_{1}$ 's probability. Meanwhile, basic event $b_{12}$ is chosen to show that the approach can generate a probability as high as $b_{12}$ 's probability.

\section{Step 1: Basic event likely occurence evaluation}

Using the experts' evaluation results in Table 3, the matrix of the failure possibilities $(Q l)$ to qualitatively express the likely occurrences of basic events $b_{1}$ and $b_{12}$ can be written as in (14).

$$
Q l=\left[\begin{array}{lllllll}
h_{4} & h_{3} & h_{3} & h_{3} & h_{3} & h_{3} & h_{3} \\
h_{5} & h_{4} & h_{5} & h_{4} & h_{5} & h_{4} & h_{5}
\end{array}\right]
$$

From Table 2, we can see that $h_{3}=$ Reasonably Low, $h_{4}=$ Moderate, and $h_{5}=$ Reasonably High .

\section{Step 2: Failure possibility fuzzification}

The matrix of the membership functions $(Q n)$ is generated by fuzzifying the matrix $Q l$ in (14) using membership functions presented in Table 2 as denoted in (15).

$$
Q n=\left[\begin{array}{lllllll}
\mu_{4}(x) & \mu_{3}(x) & \mu_{3}(x) & \mu_{3}(x) & \mu_{3}(x) & \mu_{3}(x) & \mu_{3}(x) \\
\mu_{5}(x) & \mu_{4}(x) & \mu_{5}(x) & \mu_{4}(x) & \mu_{5}(x) & \mu_{4}(x) & \mu_{5}(x)
\end{array}\right]
$$

From Table 2, we can see that

$$
\begin{aligned}
& \mu_{3}(x)=\mu_{\text {Reasonably Low }}(x)=(0.17,0.27,0.37) \\
& \mu_{4}(x)=\mu_{\text {Moderate }}(x)=(0.35,0.50,0.65) \text { and } \\
& \mu_{5}(x)=\mu_{\text {Reasonably High }}(x)=(0.63,0.73,0.83)
\end{aligned}
$$

\section{Step 3: Final membership function generation}

Using (6), the set of final membership functions $\left(M^{B}\right)$ for the membership function matrix $(Q n)$ in (15) is generated as follows. 
$M^{B}=\left[\begin{array}{l}\mu^{b_{1}}(x) \\ \mu^{b_{12}}(x)\end{array}\right]=$

$\left[\begin{array}{lllllll}(0.35,0.50,0.65) & (0.17,0.27,0.37) & (0.17,0.27,0.37) & (0.17,0.27,0.37) & (0.17,0.27,0.37) & (0.17,0.27,0.37) & (0.17,0.27,0.37) \\ (0.63,0.73,0.83) & (0.35,0.50,0.65) & (0.63,0.73,0.83) & (0.35,0.50,0.65) & (0.63,0.73,0.83) & (0.35,0.50,0.65) & (0.63,0.73,0.83)\end{array}\right]\left[\begin{array}{l}1 / 7 \\ 1 / 7 \\ 1 / 7 \\ 1 / 7 \\ 1 / 7 \\ 1 / 7 \\ 1 / 7\end{array}\right]$

$M^{B}=\left[\begin{array}{l}\mu^{b_{1}}(x) \\ \mu^{b_{12}}(x)\end{array}\right]=\left[\begin{array}{l}(0.20,0.30,0.41) \\ (0.51,0.63,0.75)\end{array}\right]$

\section{Step 4: Membership function defuzzification}

Using (7) and (8), the set of failure possibility scores $\left(R_{S}^{B}\right)$ of the set of final membership functions $\left(M^{B}\right)$ in (16) is then generated as follows.

$$
R_{S}^{B}=\left[\begin{array}{c}
R_{s}^{b_{1}} \\
R_{S}^{b_{12}}
\end{array}\right]=\left[\begin{array}{l}
A D T(0.20,0.30,0.41) \\
A D T(0.51,0.63,0.75)
\end{array}\right]=\left[\begin{array}{c}
0.083095 \\
0.190238
\end{array}\right]
$$

\section{Step 5: Basic event probability generation}

Using (9) and (10), the set of probabilities $\left(R^{B}\right)$ of the set of failure possibility scores $\left(R_{S}^{B}\right)$ in (17) is generated as follows.

$$
R^{B}=\left[\begin{array}{c}
R^{b_{1}} \\
R^{b_{12}}
\end{array}\right]=\left[\begin{array}{c}
\frac{1}{\left.10^{\left[\frac{1-0.083095}{0.083095}\right.}\right]^{1 / 3} \times 2.301} \\
\frac{1}{10} 0^{\left[\frac{1-0.190238}{0.190238}\right]^{1 / 3} \times 2.301}
\end{array}\right]=\left[\begin{array}{l}
7.54 \mathrm{E}-06 \\
1.87 \mathrm{E}-04
\end{array}\right]
$$

We can see from (18) that the probabilities of basic events $b_{1}$ and $b_{2}$ are 7.54E-06 and 1.87E-04, respectively. The same procedures shown in (14-18) are also applied to generate the probabilities of other 12 basic events in Table 1 and the results are summarized in Table 4.

\section{RESULTS AND DISCUSSION}

The probabilities of basic events of the AP1000 passive safety system involved to mitigate the large break LOCA listed in Table 1 which are generated by the proposed fuzzy reliability approach are given in Table 4 together with their relative errors.

From Table 4, we can see that the proposed fuzzy reliability approach can generate probabilities of basic events of the AP1000 passive safety system involved to mitigate the large break LOCA without the need to engage to the probability distributions of their life time to failure. In addition, the generated probabilities are also very close to the basic event probabilities used in Guimaraes et al. [16], which can be seen from the small number of relative errors between the two probabilities of the corresponding basic events. It will be interesting to see, in the future research, how the fuzzy reliability approach will perform for other components of the AP1000 passive safety system.

Table 4. Basic event probabilities.

\begin{tabular}{cccc}
\hline \multirow{2}{*}{$\begin{array}{c}\text { Basic event } \\
\text { IDs }\end{array}$} & \multicolumn{2}{c}{ Probabilities } & \multirow{2}{*}{$\begin{array}{c}\text { Relative } \\
\text { error }\end{array}$} \\
\cline { 2 - 3 } & Generated & Known & 0.006761 \\
$b_{1}$ & $7.54 \mathrm{E}-06$ & $7.59 \mathrm{E}-06$ & 0.006788 \\
$b_{2}$ & $1.12 \mathrm{E}-05$ & $1.11 \mathrm{E}-05$ & 0.006788 \\
$b_{3}$ & $1.12 \mathrm{E}-05$ & $1.11 \mathrm{E}-05$ & 0.006761 \\
$b_{4}$ & $7.54 \mathrm{E}-06$ & $7.59 \mathrm{E}-06$ & 0.06 \\
$b_{5}$ & $1.12 \mathrm{E}-05$ & $1.11 \mathrm{E}-05$ & 0.006788 \\
$b_{6}$ & $1.12 \mathrm{E}-05$ & $1.11 \mathrm{E}-05$ & 0.006788 \\
$b_{7}$ & $1.87 \mathrm{E}-04$ & $1.90 \mathrm{E}-04$ & 0.017906 \\
$b_{8}$ & $1.87 \mathrm{E}-04$ & $1.90 \mathrm{E}-04$ & 0.017906 \\
$b_{9}$ & $1.14 \mathrm{E}-04$ & $1.06 \mathrm{E}-04$ & 0.079635 \\
$b_{10}$ & $1.87 \mathrm{E}-04$ & $1.90 \mathrm{E}-04$ & 0.017906 \\
$b_{11}$ & $1.12 \mathrm{E}-05$ & $1.11 \mathrm{E}-05$ & 0.006788 \\
$b_{12}$ & $1.87 \mathrm{E}-04$ & $1.90 \mathrm{E}-04$ & 0.017906 \\
$b_{13}$ & $1.21 \mathrm{E}-04$ & $1.21 \mathrm{E}-04$ & 0.004125 \\
$b_{14}$ & $7.54 \mathrm{E}-06$ & $7.59 \mathrm{E}-06$ & 0.006761 \\
\hline
\end{tabular}

Generally, these results have demonstrated that the proposed fuzzy reliability approach can be feasibly used for reliability study of components of the AP1000 passive safety system whose historical failure data are currently unavailable. It enables experts to subjectively and individually justify component reliability characteristics based on their expertise, working experience and scientific 
intuition. Hence, it offers a more realistic approach to assess the reliability of components of AP1000 plants which are still under construction. However, if the expertise disparities of the selected experts on the AP1000 passive safety system are very substantial, the weights amongst experts will be different and, consequently, the likely occurrences of basic events justified by them will also be very different. This condition will cause the proposed fuzzy reliability approach generating higher relative errors. Hence, it is important to note that the selection of the experts will affect the generation of the basic event probabilities to some extents.

We also need to note that as soon as components of the AP1000 passive safety system have probability distributions of their lifetime to failures, conventional probabilistic reliability approach should be used. This conventional approach will generate more relevant reliability characteristics of those components.

\section{CONCLUSION}

A fuzzy reliability approach has been successfully implemented in this study to evaluate the reliability of the AP1000 passive safety system. The results of a case-based experiment show that the basic event probabilities, which are generated by the approach, are very close to the ones, which have been used by other researchers in the previous AP1000 reliability studies. This information can be inferred from the small numbers of relative errors obtained in the experiment, i.e. between 0.004125 and 0.079633. These results confirm that the fuzzy reliability approach offers a more realistic approach to assess the reliabilities of components of the AP1000 passive safety system whose probability distribution of their life time to failure are currently unavailable. It also enables experts to subjectively and individually justify the likely occurrences of basic events of the AP1000 passive safety system fault trees using qualitative failure possibilities which otherwise cannot be represented by quantitative data. For this purpose, they can utilize their expertise, working experience and scientific intuition.

\section{REFERENCES}

1. T.L. Schulz, Nucl. Eng. Des. 236 (2006) 1547.

2. A.E. Abouelnaga, A. Metwally, N. Aly, et al., Nucl. Eng. Des. 240 (2010) 2820.
3. F.C. Rahim, M. Rahgoshay and S.K. Mousavian, Prog. Nucl. Energy 54 (2012) 132.

4. S. Wang, M.I.M. Wahab and L. Fang, J. Syst. Sci. Syst. Eng. 20 (2011) 43.

5. A.K. Nayak and R.K. Sinha, Prog. Nucl. Energy 49 (2007) 486.

6. I.N. Kessides, Energy Policy 48 (2012) 185.

7. B. Sutharshan, M. Mutyala, R.P. Vijuk, et al., Energy Procedia 7 (2011) 293.

8. S.H. Chang, S.H. Kim and J.Y. Choi, Nucl. Eng. Des. 260 (2013) 104.

9. D. Lioce, M. Asztalos, A. Alemberti, et al., Nucl. Eng. Des. 250 (2012) 538.

10. S. Zhou and X. Zhang, Energy 35 (2010) 4282.

11. Y. Zhou, C. Rengito, P. Chen, et al., Energy Policy 39 (2011) 771.

12. T. Liu, J. Tong and J. Zhao, Probabilistic Risk Assessment Framework Development for Nuclear Power Plant, in: IEEE International Conference on Industrial Engineering and Engineering Management, Singapore (2008) 1330.

13. M.J. Delaney, G.E. Apostolakis and M.J. Driscoll, Nucl. Eng. Des. 235 (2005) 1537.

14. S. Kamyab, M. Nematollahi, M. Kamyab, et al., Evaluating the Reliability of AP1000 Passive Core Cooling Systems with Risk Assessment Tool, in: The International Multi Conference of Engineers and Computer Scientist, Hongkong (2010) 1668.

15. S. Kamyab and M. Nematollahi, Nucl. Eng. 253 (2012) 32.

16. A.C.F. Guimaraes, C.M.F. Lapa, F.F.L.S. Filho, et al., Ann. Nucl. Energy 38 (2011) 1775.

17. T. Zhou, J. Chen, F. Luo, et al., Nucl. Eng. Des. 247 (2012) 230.

18. J.H. Purba, J. Lu, G. Zhang, et al., Fuzzy Sets Syst. 243 (2014) 50.

19. J.H. Purba, Ann. Nucl. Energy 70 (2014) 21.

20. J.H. Purba, J. Lu and G. Zhang, Fuzzy Failure Rate for Nuclear Power Plant Probabilistic Safety Assessment by Fault Tree Analysis, in: Computational Intelligence Systems in Industrial Engineering, C. Kahraman (Ed.), Atlantis Press, France (2012) 131.

21. M. Valette, J. Pouvreau, D. Bestion, et al., Nucl. Eng. Des. 241 (2011) 4487. 
22. R.A. Matzie, Nucl. Eng. Des. 238 (2008) 1856.

23. W.E. Cummins, M.M. Corletti and T.L. Schulz, Westinghouse AP1000 Advanced Passive Plant, in: International Congress on Advances in Nuclear Power Plants, Spain (2003) 3235.

24. J.H. Purba, J. Lu, D. Ruan, et al., Int. J. Comput. Intell. Appl. 11 (2012) 1250022. 